\title{
Predictors of Cure of Intrahepatic Cholangiocarcinoma After Hepatic Resection
}

\author{
MASAYO TSUKAMOTO ${ }^{1}$, YO-ICHI YAMASHITA ${ }^{1}$, KATSUNORI IMAI $^{1}$, \\ NAOKI UMEZAKI ${ }^{1}$, TAKANOBU YAMAO ${ }^{1}$, HIROHISA OKABE ${ }^{1}$, SHIGEKI NAKAGAWA ${ }^{1}$, \\ DAISUKE HASHIMOTO ${ }^{1}$, AKIRA CHIKAMOTO ${ }^{1}$, TAKATOSHI ISHIKO ${ }^{1}$, \\ TOMOHARU YOSHIZUMI ${ }^{2}$, YOSHIHIKO MAEHARA ${ }^{2}$ and HIDEO BABA ${ }^{1}$ \\ ${ }^{1}$ Department of Gastroenterological Surgery, Kumamoto University Graduate School of Life Sciences, Kumamoto, Japan \\ ${ }^{2}$ Department of Surgery and Science, Graduate School of Medical Sciences, Kyushu University, Fukuoka, Japan
}

\begin{abstract}
Background/Aim: Intrahepatic cholangiocarcinoma (ICC) is the second most common primary liver cancer after hepatocellular carcinoma, and has a poor prognosis. Surgical resection is the only option for a cure of ICC. Here we attempted to define the cure rate after hepatic resection for ICC and to identify the predictors for a cure. Patients and Methods: Among the 96 patients who underwent $R 0$ resections for primary ICC between 1990 and 2011 at the Kumamoto University Hospital and Kyushu University Hospital, those who were followed for $\geq 5$ years after surgery were enrolled. "Cure" was defined as recurrence-free survival (RFS) of $\geq 5$ years after surgery. Results: A total of 81 patients were eligible. A cure was achieved in 37 patients (45.7\%). The 5-year overall survival and RFS rates were $55.0 \%$ and $41.7 \%$, respectively. A multivariate logistic regression analysis identified the absence of lymph node metastasis (relative risk $(R R) 7.5, p=0.011)$ and the absence of microvascular invasion ( $R R$ 5.5, $p=0.0137$ ) as the independent predictors of achieving a cure. Conclusion: $R O$ resections achieved a cure in $45.7 \%$ of this series of ICC patients. The predictors of a cure identified here, i.e., absence of lymph node metastasis and absence of microvascular invasion, could contribute to the selection of patients who are not candidates for adjuvant chemotherapy.
\end{abstract}

Intrahepatic cholangiocarcinoma (ICC) is a malignant tumor arising from the epithelial cells of the intrahepatic bile duct, and ICCs are located within the hepatic parenchyma. ICC is the second most common primary liver cancer after

Correspondence to: Dr. Yo-ichi Yamashita, Department of Gastroenterological Surgery, Kumamoto University Graduate School of Medical Sciences 1-1-1 Honjo, Kumamoto, 860-8556 Japan. Tel: +81963735212, Fax: +81963714378, e-mail: y-yama@kumamotou.ac.jp

Key Words: Intrahepatic cholangiocarcinoma, hepatic resection. hepatocellular carcinoma, and ICCs account for $5-15 \%$ of all primary liver cancers in Japan (1-3). As ICC cases are always asymptomatic, only $20-40 \%$ of ICC patients are operable at the time of their presentation (4-6); ICC is thus one of the poor-prognosis cancers. Surgical resection is still the only option for long-term survival and a potential cure.

However, the surgical outcomes for ICC remain unsatisfactory with a 5-year survival rate of $23.6-35 \%(1,4$, $7,8)$ and $58 \%$ even after R0 resection $(1,9)$. The rate of recurrence was also reported to be high, at $53-71 \%(4,10$, 11). The reported poor prognostic factors for ICC are lymph node metastasis, microvascular invasion, tumor size $\geq 5 \mathrm{~cm}$, and multiple tumors $(1,7,10)$. Data regarding the prediction of ICC recurrence could contribute to the decisions regarding treatment strategies. That is, knowledge of reliable predictors of recurrence could suggest indications for selecting patients who need adjuvant chemotherapy.

In this study, we investigated the cure rate after R0 resection for ICC, based on the 5-year recurrence-free survival (RFS), and we identified the predictors of achieving a cure.

\section{Patients and Methods}

Patients. From 1990 to 2011, we treated 121 patients for primary ICC at Kumamoto University Hospital and Kyushu University Hospital. After the exclusion of patients with $R 1 / R 2$ resection $(n=23)$ or operative mortality $(n=2), 96$ patients were enrolled in this study. After the exclusion of patients who are not completed 5-year followup $(\mathrm{n}=11)$ and those who deceased due to diseases other than ICC $(n=4), 81$ patients were followed for $\geq 5$ years after surgery. "Cure" was defined as RFS of $\geq 5$ years after surgery. The median follow-up time of our series was 45 months (range $=0.43-197$ months).

Surgical techniques. The details of our surgical techniques and the follow-up methods have been reported $(1,9,12,13)$. Major hepatic resection (HR) with bile duct resection was performed when bile duct invasion of ICC was suspected to have affected the first hepatic duct. Partial HR was performed in cases of peripheral ICC without bile duct invasion. When we considered that it would be better to confirm the 

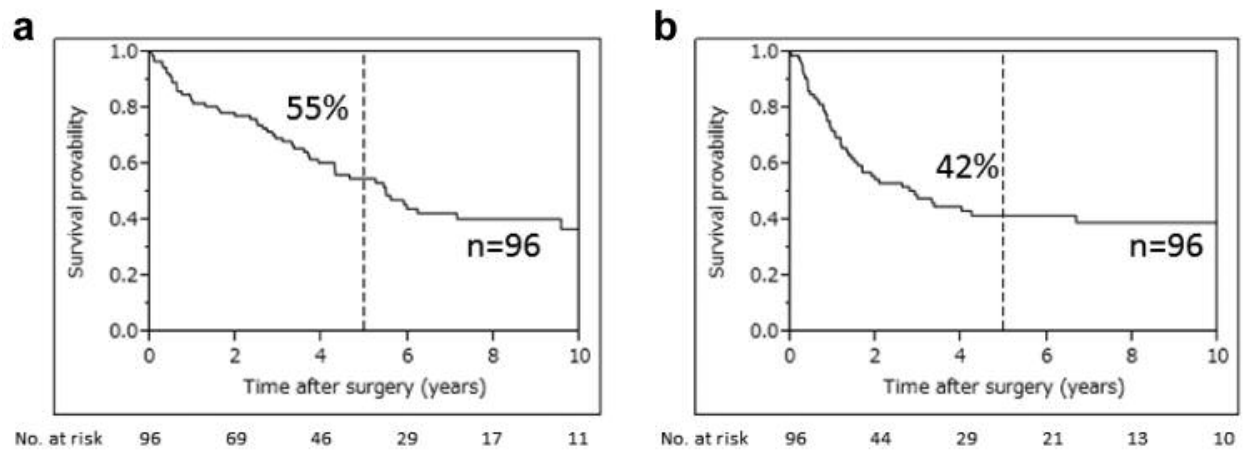

Figure 1. Survival curves related to OS and RFS. OS ( $a$ ) and) RFS ( $b$ after surgery.

negative surgical margin, the surgical stump was preserved for frozen pathology (1). As the right and left lobes of the liver have different routes of lymphatic drainage, the style of lymph node dissection was different according to the tumor location on the right or left lobe (12).

Ethical approval: All procedures performed in studies involving human participants were in accordance with the ethical standards of the institutional and/or national research committee and with the 1964 Helsinki declaration and its later amendments or comparable ethical standards. Informed consent was obtained from all individual participants included in the study.

Statistical analysis. Continuous variables are expressed as means \pm standard deviation (SD) and were compared using Student's $t$-test. Categorical variables were compared using either the $\chi^{2}$ test or Fisher's exact test, as appropriate. Grade II or higher complications according to the Clavien-Dindo classification were recorded as morbidity (14). The overall survival (OS) and RFS curves were generated by the Kaplan-Meier method and compared by the log-rank test. We subjected the variables that exhibited a probability $(p)$ value $<0.05$ in a univariate analysis to a multivariate analysis using a multivariate logistic regression model. All analyses were performed using JMP ${ }^{\circledR}$ Pro 9.0.2 software (SAS, Cary, NC). $p$-Values $<0.05$ were considered significant.

\section{Results}

Patients' prognoses. A potential cure was achieved in 37 of the 81 patients $(45.7 \%)$. The survival curves related to OS and RFS are illustrated in Figure 1. The 5-year OS rate for the complete series was $55.0 \%$, and the median OS time was 5.5 years. For the complete series, the 5-year RFS rate was $41.7 \%$, and the median RFS time was 2.8 years.

Patients' clinicopathological characteristics. The clinical characteristics of the cured $(n=37)$ and non-cured $(n=44)$ groups in our series are summarized in Table I. There were no significant differences in any variables between the two groups. The surgical factors of the two groups are summarized in Table II. Hepatic resection of two or more segments was performed in $54 \%$ of the cured group (20 patients) and $75 \%$ of the non-cured group (33 patients) $(p=0.048)$. The median operation time was 402 (range $=200-785 \mathrm{~min}$ ) $\mathrm{min}$ in the cured group and significantly longer, i.e., 483 (range $=142$ $755 \mathrm{~min}$ ) $\mathrm{min}$ in the non-cured group $(p=0.032)$.

Our comparison of tumor-related factors in the two groups is summarized in Table III. The median tumor size was 3.3 (range $=1.1-12 \mathrm{~cm}$ ) $\mathrm{cm}$ in the cured group and significantly higher at 4.5 (range $=1.6-11 \mathrm{~cm}) \mathrm{cm}$ in the non-cured group $(p=0.014)$. Invasion of the serosa was recognized at a significantly higher rate in the non-cured group $(63 \% ; 27$ patients) compared to the cure group (38\%; 14 patients) $(p=0.026)$. Microvascular invasion was recognized in 12 curegroup patients $(34 \%)$ and 31 non-cured patients $(70 \%)$ $(p=0.0013)$. Pathological intrahepatic metastasis was identified in six patients $(21 \%)$ of the cure group and 16 patients $(46 \%)$ of the non-cured group $(p=0.045)$. Lymph node metastasis was recognized in $11 \%$ (4 patients) of the cure group and 50\% (17 patients) of the non-cured group ( $p=0.0093)$.

Univariate and multivariate analysis of predictors for a cure. The univariate analysis revealed the following as predictors of a cure: operation time $<500 \mathrm{~min}$. ( $p=0.0073)$, hepatic resection of $<2$ segments $(p=0.048)$, tumor diameter $<3 \mathrm{~cm}(p=0.0032)$, absence of invasion of the serosa $(p=0.026)$, absence of microvascular invasion $(p=0.0013)$, absence of pathologic intrahepatic metastasis $(p=0.045)$ and absence of lymph node metastasis $(p=0.0093)$ (Table IV). The multivariate logistic regression analysis identified the absence of lymph node metastasis (relative risk (RR) 7.5, $p=0.0110$ ) and the absence of microvascular invasion ( $R R$ 5.5, $p=0.0137$ ) as the independent predictors for achieving a cure (Table V).

\section{Discussion}

A cure was achieved in $45.7 \%$ of the 81 patients with ICC after $\mathrm{R} 0$ resection in the present series. This is higher than the previously reported cure rates of $27 \%-37 \%$ in ICC patients $(10,15,16)$. This may be because surgical procedures and multidisciplinary therapy for ICC have 
Table I. Comparisons of clinical characteristics between the cured and non-cured groups.

\begin{tabular}{lccc}
\hline Variables & $\begin{array}{c}\text { Cured } \\
(\mathrm{n}=37)\end{array}$ & $\begin{array}{c}\text { Non-cured } \\
(\mathrm{n}=44)\end{array}$ & $p$-Value \\
\hline Age & $67 \pm 10.7$ & $59 \pm 11.6$ & 0.097 \\
Gender (Male:Female) & $19: 18$ & $25: 19$ & 0.62 \\
BMI & $20.9 \pm 2.8$ & $22.6 \pm 4.0$ & 0.18 \\
HBV/HCV/nonB nonC & $6: 7: 22$ & $9: 6: 29$ & 0.73 \\
Alb $(\mathrm{g} / \mathrm{dl})$ & $4.1 \pm 0.4$ & $4.1 \pm 0.4$ & 0.73 \\
T-bil (mg/dl) & $0.7 \pm 2.1$ & $0.7 \pm 0.6$ & 0.52 \\
AST $\geq 40(\mathrm{IU} / \mathrm{L})$ & $9(24 \%)$ & $15(34 \%)$ & 0.34 \\
ALT $\geq 40(\mathrm{IU} / \mathrm{L})$ & $10(27 \%)$ & $16(36 \%)$ & 0.37 \\
Plt $(104 / \mu \mathrm{l})$ & $22 \pm 96.5$ & $23 \pm 113$ & 0.61 \\
PT $(\%)$ & $99 \pm 15$ & $100 \pm 11$ & 0.26 \\
Liver damage A/B & $35 / 1$ & $40 / 4$ & 0.25 \\
ICG R15 (\%) & $8.5 \pm 10$ & $10.6 \pm 11$ & 0.43 \\
\hline
\end{tabular}

Table II. Comparisons of surgical factors between the cured and noncured groups.

\begin{tabular}{lccc}
\hline Variables & $\begin{array}{c}\text { Cured } \\
(\mathrm{n}=37)\end{array}$ & $\begin{array}{c}\text { Non-cured } \\
(\mathrm{n}=44)\end{array}$ & $p$-Value \\
\hline $\begin{array}{l}\text { Hepatic resection } \\
\quad(2 \text { segments })\end{array}$ & $20(54 \%)$ & $33(75 \%)$ & 0.048 \\
Lymphadenectomy & $17(46 \%)$ & $26(59 \%)$ & 0.24 \\
Operation time(min.) & $402 \pm 145$ & $483 \pm 132$ & 0.032 \\
Bleeding(g) & $604 \pm 2699$ & $770 \pm 937$ & 0.84 \\
Transfusion & $12(33 \%)$ & $10(24 \%)$ & 0.39 \\
Complication & $16(43 \%)$ & $17(39 \%)$ & 0.83 \\
$\quad$ Clavien-Dindo $\geq \mathrm{II})$ & & & \\
\hline
\end{tabular}

progressed over the past decade, with the use of agents such as gemcitabine plus cisplatin or S-1. However, a standard therapy for recurrence or adjuvant chemotherapy against ICC has not been established (17-22).

ICC is a relatively rare disease, and R0 resections for ICC are also relatively rare. The limitations of this study include its retrospective nature and relatively small sample size, despite its collection of data from two high-volume liver cancer centers in Japan. Multi-institutional studies of larger numbers of patients are warranted to test our present findings.

We identified two independent predictors for a cure of ICC; the absence of lymph node metastasis and the absence of microvascular invasion. These factors were previously reported to be poor-prognosis factors in ICC patients who have undergone resections; that is, several studies reported lymph node metastasis $(1,7,10,15,23)$, microvascular invasion $(7,10)$, tumor size $\geq 5 \mathrm{~cm}(10,15,23)$ and multiple tumors $(7,23)$ as poor-prognosis factors. In our present analysis too, only tumor-related factors and no clinical or surgical factors were identified as predictors of a cure.
Table III. Comparisons of tumor-related factors between the cured and non-cured groups.

\begin{tabular}{lccc}
\hline Variables & $\begin{array}{c}\text { Cured } \\
(\mathrm{n}=37)\end{array}$ & $\begin{array}{c}\text { Non-cured } \\
(\mathrm{n}=44)\end{array}$ & $p$-Value \\
\hline CEA $(\mathrm{ng} / \mathrm{ml}))$ & $1.6 \pm 3.3$ & $1.9 \pm 19$ & 0.13 \\
CA19-9 $(\mathrm{U} / \mathrm{ml})$ & $18 \pm 111714$ & $30 \pm 17845$ & 0.21 \\
Tumor size $(\mathrm{cm})$ & $3.3 \pm 2.4$ & $4.5 \pm 2.3$ & 0.014 \\
Tumor number (single/multiple) & $30: 7$ & $29: 15$ & 0.13 \\
Growth type (eg/ig) & $22: 15$ & $31: 13$ & 0.30 \\
Invasion of the serosa & $14(38 \%)$ & $27(63 \%)$ & 0.026 \\
Microvascular invasion & $12(34 \%)$ & $31(70 \%)$ & 0.0013 \\
Bile duct invasion & $11(33 \%)$ & $18(44 \%)$ & 0.35 \\
Intrahepatic metastasis & $6(21 \%)$ & $16(46 \%)$ & 0.045 \\
Lymph node metastasis & $4(11 \%)$ & $17(50 \%)$ & 0.0093 \\
\hline
\end{tabular}

Unfortunately, the absence of lymph node metastasis and the absence of microvascular invasion can be determined only after surgery, but these factors are still valuable when considering indications for adjuvant chemotherapy for ICC patients after R0 resections. For example, it was reported that the patients who showed the greatest benefit from adjuvant therapy were those with lymph node metastasis (24). That is, patients without factors such as lymph node metastasis or microvascular invasion need not receive adjuvant chemotherapy after $\mathrm{R} 0$ resections.

We also performed a receiver operating curve (ROC) analysis to determine the diagnostic accuracy of the identified risk factors for cure. Using the predictor of absence of lymph node metastasis, the sensitivity was $38.6 \%$ and the specificity was $89.2 \%$. Using the predictor of absence of microvascular invasion, the sensitivity was $70.5 \%$ and the specificity was $65.7 \%$. Thus, high specificity $(89.2 \%)$ was observed for absence of lymph node metastasis as a predictor, whereas high sensitivity (70.5\%) was observed for absence of microvascular invasion. In the future, when ICC recurrence is being treated by using drugs with a risk of severe adverse events, lymph node metastasis rather than microvascular invasion should be adopted as a factor when considering indications for adjuvant chemotherapy.

Moreover, with the use of both absence of lymph node metastasis and absence of microvascular invasion as predictors, the sensitivity was $60.0 \%$ and the specificity was $90.9 \%$. We propose that for selecting contra-indications for adjuvant chemotherapy, high specificity is critical rather than high sensitivity. The indications for adjuvant chemotherapy can be accurately identified by using our two predictors of a cure. A model to predict a cure with higher accuracy along with advances in molecular targeted therapies and radiation techniques are needed (25).

In conclusion, we achieved a potential cure in $45.7 \%$ of 81 patients with ICC who underwent $\mathrm{R} 0$ resections, and identified the absence of lymph node metastasis and the absence of microvascular invasion as the independent predictors of a cure. 
Table IV. Univariate analysis of factors that predicted a cure.

\begin{tabular}{|c|c|c|c|}
\hline Variables & $\begin{array}{l}\text { Cured } \\
(\mathrm{n}=37)\end{array}$ & $\begin{array}{l}\text { Non-cured } \\
(\mathrm{n}=44)\end{array}$ & $p$-Value \\
\hline \multicolumn{4}{|l|}{ BMI } \\
\hline$\leq 25$ & 30 & 36 & \multirow[t]{2}{*}{0.86} \\
\hline$>25$ & 6 & 8 & \\
\hline \multicolumn{4}{|l|}{$\mathrm{Alb}(\mathrm{g} / \mathrm{dl})$} \\
\hline$\leq 4.0$ & 16 & 18 & \multirow[t]{2}{*}{0.83} \\
\hline$>4.0$ & 21 & 26 & \\
\hline \multicolumn{4}{|c|}{ T-bil (mg/dl) } \\
\hline$\leq 1.0$ & 30 & 35 & \multirow[t]{2}{*}{0.86} \\
\hline$>1.0$ & 7 & 9 & \\
\hline \multicolumn{4}{|l|}{ AST } \\
\hline$\leq 40$ & 28 & 29 & \multirow[t]{2}{*}{0.34} \\
\hline$>40$ & 9 & 15 & \\
\hline \multicolumn{4}{|l|}{ ALT } \\
\hline$\leq 40$ & 27 & 28 & \multirow[t]{2}{*}{0.37} \\
\hline$>40$ & 10 & 16 & \\
\hline \multicolumn{4}{|c|}{ Plt $\left(10^{4} / \mu \mathrm{l}\right)$} \\
\hline$\leq 10$ & 29 & 28 & \multirow[t]{2}{*}{0.15} \\
\hline$>10$ & 8 & 16 & \\
\hline \multicolumn{4}{|l|}{ PT (\%) } \\
\hline$<100$ & 20 & 16 & \multirow[t]{2}{*}{0.11} \\
\hline$\geq 100$ & 17 & 28 & \\
\hline \multicolumn{4}{|c|}{ Liver damage } \\
\hline A & 35 & 40 & \multirow[t]{2}{*}{0.25} \\
\hline $\mathrm{B}$ & 1 & 4 & \\
\hline \multicolumn{4}{|c|}{ ICG R15 (\%) } \\
\hline$<10$ & 17 & 20 & \multirow[t]{2}{*}{0.51} \\
\hline$\geq 10$ & 15 & 24 & \\
\hline \multicolumn{4}{|c|}{ CEA (ng/ml) } \\
\hline$<5.0$ & 33 & 34 & \multirow[t]{2}{*}{0.22} \\
\hline$\geq 5.0$ & 4 & 9 & \\
\hline \multicolumn{4}{|c|}{ CA19-9 (mAU/ml) } \\
\hline$<40$ & 21 & 24 & \multirow[t]{2}{*}{0.93} \\
\hline$\geq 40$ & 16 & 19 & \\
\hline \multicolumn{4}{|c|}{ Tumor size $(\mathrm{cm})$} \\
\hline$<3$ & 17 & 7 & \multirow[t]{2}{*}{0.0032} \\
\hline$\geq 3$ & 20 & 37 & \\
\hline
\end{tabular}

\section{Conflicts of Interest}

Masayo Tsukamoto and other co-authors have no conflicts of interest concerning of this work.

\section{References}

1 Yamashita Y, Taketomi A, Morita K, Fukuhara T, Ueda S, Sanefuji K, Iguchi T, Kayashima H, Sugimachi K and Maehara $\mathrm{Y}$ : The impact of surgical treatment and poor prognostic factors for patients with intrahepatic cholangiocarcinoma: retrospective analysis of 60 patients. Anticancer Res 28: 2353-2359, 2008.

2 Liver Cancer Study Group of Japan: Primary liver cancer in Japan. Clinicopathologic features and results of surgical treatment. Ann Surg 211: 277-287, 1990.

\begin{tabular}{|c|c|c|c|}
\hline Variables & $\begin{array}{l}\text { Cured } \\
(\mathrm{n}=37)\end{array}$ & $\begin{array}{c}\text { Non-cured } \\
\quad(n=44)\end{array}$ & $p$-Value \\
\hline \multicolumn{4}{|c|}{ Tumor number } \\
\hline single & 30 & 29 & \multirow[t]{2}{*}{0.13} \\
\hline multiple & 7 & 15 & \\
\hline \multicolumn{4}{|c|}{ Hepatic resection (segments) } \\
\hline$<2$ & 17 & 11 & \multirow[t]{2}{*}{0.048} \\
\hline$\geq 2$ & 20 & 33 & \\
\hline \multicolumn{4}{|c|}{ Lymphadenectomy } \\
\hline Yes & 17 & 26 & \multirow[t]{2}{*}{0.24} \\
\hline No & 20 & 18 & \\
\hline \multicolumn{4}{|c|}{ Operation time } \\
\hline$<500$ & 30 & 22 & \multirow[t]{2}{*}{0.0073} \\
\hline$\geq 500$ & 7 & 20 & \\
\hline \multicolumn{4}{|l|}{ Bleeding } \\
\hline$<1900$ & 28 & 37 & \multirow[t]{2}{*}{0.15} \\
\hline$\geq 1900$ & 9 & 5 & \\
\hline \multicolumn{4}{|l|}{ Transfusion } \\
\hline Yes & 12 & 10 & \multirow[t]{2}{*}{0.39} \\
\hline No & 24 & 31 & \\
\hline \multicolumn{4}{|c|}{ Complication } \\
\hline Yes & 16 & 17 & \multirow[t]{2}{*}{0.83} \\
\hline No & 21 & 27 & \\
\hline \multicolumn{4}{|c|}{ Growth type } \\
\hline eg & 22 & 31 & \multirow[t]{2}{*}{0.30} \\
\hline ig & 15 & 13 & \\
\hline \multicolumn{4}{|c|}{ Invasion of the serosa } \\
\hline Yes & 14 & 27 & \multirow[t]{2}{*}{0.026} \\
\hline No & 23 & 16 & \\
\hline \multicolumn{4}{|c|}{ Microvascular invasion } \\
\hline Yes & 12 & 31 & \multirow[t]{2}{*}{0.0013} \\
\hline No & 23 & 13 & \\
\hline \multicolumn{4}{|c|}{ Bile duct invasion } \\
\hline Yes & 11 & 18 & \multirow[t]{2}{*}{0.35} \\
\hline No & 22 & 23 & \\
\hline \multicolumn{4}{|c|}{ Intrahepatic metastasis } \\
\hline Yes & 6 & 16 & \multirow[t]{2}{*}{0.045} \\
\hline No & 22 & 19 & \\
\hline \multicolumn{4}{|c|}{ Lymph node metastasis } \\
\hline Yes & 4 & 17 & \multirow[t]{2}{*}{0.0044} \\
\hline No & 33 & 27 & \\
\hline
\end{tabular}

Table V. Multivariate analysis of predictors for a cure.

\begin{tabular}{lccc}
\hline Variables & $\mathrm{RR}$ & $95 \% \mathrm{CI}$ & $p$-Value \\
\hline Lymph node metastasis (-) & 7.5 & $1.55-49.1$ & 0.0110 \\
Microvascular invasion (-) & 5.5 & $1.41-25.2$ & 0.0137 \\
Operation time <500 minutes & 3.1 & $0.777-13.7$ & 0.1086 \\
Tumor size $<3 \mathrm{~cm}$ & 2.6 & $0.573-12.6$ & 0.2142 \\
Intrahepatic metastasis (-) & 1.5 & $0.341-6.81$ & 0.5994 \\
Invasion of the serosa (-) & 1.4 & $0.333-6.19$ & 0.6705 \\
Hepatic resection <2 segments & 1.3 & $0.318-5.67$ & 0.7122 \\
\hline
\end{tabular}

3 Uenishi T, Hirohashi K, Kubo S, Yamamoto T, Yamazaki O and Kinoshita H: Clinicopathological factors predicting outcome 
after resection of mass-forming intrahepatic cholangiocarcinoma Br J Surg 88: 969-974, 2001.

4 Spolverato G, Kim Y, Alexandrescu S, Marques HP, Lamelas J, Aldrighetti L, Clark Gamblin T, Maithel SK, Pulitano C, Bauer TW, Shen F, Poultsides GA, Tran TB, Wallis Marsh J and Pawlik TM: Management and Outcomes of Patients with Recurrent Intrahepatic Cholangiocarcinoma Following Previous CurativeIntent Surgical Resection. Ann Surg Oncol 23: 235-243, 2016.

5 Weber SM, Jarnagin WR, Klimstra D, DeMatteo RP, Fong Y and Blumgart LH: Intrahepatic cholangiocarcinoma: resectability, recurrence pattern, and outcomes. J Am Coll Surg 193: 384-391, 2001 .

6 Amini N, Ejaz A, Spolverato G, Kim Y, Herman JM and Pawlik TM: Temporal trends in liver-directed therapy of patients with intrahepatic cholangiocarcinoma in the United States: a population-based analysis. J Surg Oncol 110: 163-170, 2014.

7 De Jong MG, Nathan H, Sotiropoulos GC, Paul A, Alexandrescu S, Marques H, Pulitano C, Barroso E, Clary BM, Aldrighetti L, Ferrone CR, Zhu AX, Bauer TW, Walters DM, Gamblin TC, Nguyen KT, Turley R, Popescu I, Hubert C, Meyer S, Schulick RD, Choti MA, Gigot JF, Mentha G and Pawlik TM: Intrahepatic cholangiocarcinoma: an international multiinstitutional analysis of prognostic factors and lymph node assessment. J Clin Oncol 29: 3140-3145, 2011.

8 Nuzzo G, Giuliante F, Ardito F, De Rose AM, Vellone M, Clemente G, Chiarla $\mathrm{C}$ and Giovannini I: Intrahepatic cholangiocarcinoma: prognostic factors after liver resection. Updates Surg 62: 11-19, 2010.

9 Yamashita Y, Wang H, Kurihara T, Tsujita E, Nishie A, Imai K, Hashimoto D, Chikamoto A, Aishima S and Baba H: Clinical significances of preoperative classification of intrahepatic cholangiocarcinoma: different characteristics of perihilar $v s$. peripheral ICC. Anticancer Res 36: 6563-6570, 2016.

10 Hyder O, Hatzaras I, Sotiropoulos GC, Paul A, Alexandrescu S, Marques H, Pulitano C, Barroso E, Clary BM, Aldrighetti L, Ferrone CR, Zhu AX, Bauer TW, Walters DM, Groeschl R, Gamblin TC, Marsh JW, Nguyen KT, Turley R, Popescu I, Hubert C, Meyer S, Choti MA, Gigot JF, Mentha G and Pawlik TM: Recurrence after operative management of intrahepatic cholangiocarcinoma. Surgery 153: 811-818, 2013.

11 Spolverato G, Kim Y, Ejaz A, Alexandrescu S, Marques H, Aldrighetti L, Gamblin TC, Pulitano C, Bauer TW, Shen F, Sandroussi C and Poultsides G: Conditional probability of longterm survival after liver resection for intrahepatic cholangiocarcinoma: A multi-institutional analysis of 535 patients. JAMA 150: 538-545, 2015.

12 Shimada M, Yamashita Y, Aishima S, Shirabe K, Takenaka K and Sugimachi K: Value of lymph node dissection during resection of intrahepatic cholangiocarcinoma. Br J Surg 88: 1463-1466, 2011.

13 Shirabe K, Mano Y, Taketomi A, Soejima Y, Uchiyama H, Aishima S, Kayashima H, Ninomiya $M$ and Maehara $Y$ : Clinicopathological prognostic factors after hepatectomy for patients with mass-forming type intrahepatic cholangiocarcinoma: relevance of the lymphatic invasion index. Ann Surg Oncol 17: 1816-1822, 2010.

14 Dindo D, Demartines N and Clavien PA: Classification of surgical complications: a new proposal with evaluation in a cohort of 6336 patients and results of a survey. Ann Surg 240: 205-213, 2004.
15 Chen LP, Li C, Wang C, Wen TF, Yan LN and Li B: Predictive factors of recurrence for patients with intrahepatic cholangiocarcinoma after hepatectomy. Hepatogastroenterology 59: 1765$1768,2012$.

16 Hanazaki K, Kajikawa S, Shimozawa N, Shimada K, Hiraguri M, Koide N, Adachi W and Amano J: Prognostic factors of intrahepatic cholangiocarcinoma after hepatic resection: univariate and multivariate analysis. Hepatogastroenterology 49 : 311-316, 2002.

17 Eckel F and Schmid RM: Chemotherapy in advanced biliary tract carcinoma: a pooled analysis of clinical trials. Br J Cancer 96: 896-902, 2007.

18 Valle J, Wasan H, Palmer DH, Cunningham D, Anthoney A, Maraveyas A, Madhusudan S, Iveson T, Hughes S, Pereira SP, Roughton M, Bridgewater J; ABC-02 Trial Investigators: Cisplatin plus gemcitabine versus gemcitabine for biliary tract cancer. N Engl J Med 362: 1273-1281, 2010.

19 Ueno H, Okusaka T, Ikeda M, Takezako Y and Morizane C: Phase II study of S-1 in patients with advanced biliary tract cancer. Br J Cancer 91: 1769-1774, 2004.

20 Sasaki T, Isayama H, Nakai Y, Ito Y, Kogure H, Togawa O, Toda N, Yasuda I, Hasebe O, Maetani I, Sasahira N, Hirano K, Tsujino $\mathrm{T}$, Tada $\mathrm{M}$ and Omata $\mathrm{M}$ : Multicenter, phase II study of gemcitabine and S-1 combination chemotherapy in patients with advanced biliary tract cancer. Cancer Chemother Pharmacol 65: 1101-1107, 2010.

21 Murakami Y, Uemura K, Sudo T, Hashimoto Y, Nakashima A, Sakabe R, Kobayashi H, Kondo N, Nakagawa N and Sueda T: Adjuvant chemotherapy with gemcitabine and S-1 after surgical resection for advanced biliary carcinoma: outcomes and prognostic factors. J Hepatobiliary Pancreat Sci 19: 306-313, 2012.

22 Miura JT, Johnson FM, Tsai S, George B, Thomas J, Eastwood D, Banerjee A, Christians KK, Turaga KK, Pawlik TM and Clark Gamblin T: Chemotherapy for surgical resected intrahepatic cholangiocarcinoma. Ann Surg Oncol 22: 37163723, 2015.

23 Endo I, Gonen M, Yopp AC, Dalal KM, Zhou Q, Klimstra D, D'Angelica M, DeMatteo RP, Fong Y, Schwartz L, Kemeny N, O'Reilly E, Abou-Alfa GK, Shimada H, Blumgart LH and Jamagin WR: Intrahepatic cholangiocarcinoma: rising frequency, improved survival, and determinants of outcome after resection. Ann Surg 248: 84-96, 2008.

24 Horgan AM, Amir E, Walter T and Knox JJ: Adjuvant therapy in the treatment of biliary tract cancer: a systematic review and meta-analysis. J Clin Oncol 30: 1934-1940, 2012.

25 Williams TM, Majithia L, Wang SJ and Thomas CR Jr.: Defining the role of adjuvant therapy: cholangiocarcinoma and gall bladder cancer. Semin Radiat Oncol 24: 94-104, 2014.

26 Imai K, Castro Benitez C, Allard M-A, Vibert E, Sa Cunha A, Cherqui D, Castaing D, Bismuth $\mathrm{H}$, Baba $\mathrm{H}$ and Adam R: Potential of a cure in patients with colorectal liver metastasis and concomitant extrahepatic disease. J Surg Oncol 9999: 1-9, 2016.

27 Miwa S, Miyagawa S, Kobayashi A, Akahane Y, Nakata T, Mihara M, Kusama K, Soeda J and Ogawa S: Predictive factors for intrahepatic cholangiocarcinoma recurrence in the liver following surgery. J Gastroenterol 41: 893-900, 2006.

Received September 12, 2017

Revised October 7, 2017

Accepted October 11, 2017 